Aletria, Belo Horizonte, v. 29, n. 4, p. 85-111, 2019

\title{
A coralidade e o mundo das parthénoi na poesia mélica de Safo
}

\section{Chorality and the World of Parthénoi in Sappho's Melic Poetry}

Giuliana Ragusa

Universidade de São Paulo (USP), São Paulo, São Paulo / Brasil

gragusa@usp.br

Resumo: O artigo estuda a coralidade da poesia mélica (ou lírica) de Safo (Lesbos, c. 630-580 a.C.), na Grécia arcaica (c. 800-480 a.C.), e sua relação com o universo das parthénoi - as virgens ou moças ainda não casadas -, um dos elementos mais característicos e nítidos em seu corpus de fragmentos preservados. Para tanto, parte de um dos mais recentes, a "Canção sobre a velhice", publicada em 2005, que provocou a rediscussão da dimensão coral das canções de Safo, e da natureza do grupo feminino de parthénoi a ela associado. O objetivo é reavaliar a relação entre a poeta e sua comunidade, pensando seu papel como líder das jovens e a função da coralidade na vida das jovens.

Palavras-chave: Safo; poesia grega arcaica; mélica; coralidade; virgens.

Abstract: The article studies the chorality of Sappho's (Lesbos, c. 630-580 BC) melic (or lyric) poetry, in archaic Greece (c. 800-480 BC), and its relation to the world of parthéno - the maidens, the unmarried girls - that is one of the main and most visible elements of her surviving corpus of fragments. In order to do so, it focuses on one of the most recently discovered fragments of Sappho, the "Old age song", published in 2005, for it has provoked a reassessment of the relations between the poet and her community, of her role as leader of the maidens and of the function of chorality in the life of the parthénoi.

Keywords: Sappho; archaic Greek poetry; melic; chorality; maidens. 
A coralidade da mélica (ou lírica) grega arcaica de Safo (c. 630-580 a.C., ilha de Lesbos) é o aspecto que tem sido repensado e revalorizado como fundamental à compreensão de sua poesia e de seu universo, e sobretudo, da relação entre a poeta e seu grupo de moças não asadas ou virgens - as parthénoi, termo técnico que define esse status transitório -, desde a publicação em 2005 de um dos novos fragmentos sáficos, a "Canção sobre a velhice", que foi decisivo para o retorno com novas lentes ao corpus da poeta. Combinou-se a esse estimulante fato o enfoque intensificado na performance da mélica grega arcaica, e o resultado tem sido a avaliação mais precisa da produção de Safo, e a ampliação da distância das leituras biografizantes e romantizadas, que tanto buscam na poeta o que é estranho à sua poesia e, em verdade, à poesia antiga como um todo: a voz pessoal, o subjetivismo, o intimismo, a privacidade, os sentimentos confessos do "eu". Conforme as palavras de Katerina Ladianou,

À luz do Romantismo, a poesia de Safo tem sido lida como uma expressão dos sentimentos íntimos da poeta. De acordo com esse modelo, Safo é uma solista, cantando suas canções e tocando sua lira em um espaço privado, num círculo pequeno de companheiras do mesmo sexo. ${ }^{1}$

A propósito dessa ideia que por tanto tempo perdurou - e de certo modo, em certas leituras modernizantes vinculadas a questões de gênero e sexualidade, ainda perdura -, vale recordar, como bem afirma Franco Ferrari, que "não há indicação da existência de composições poéticas da Grécia arcaica e clássica, ao menos de Homero a Eurípides, que não fossem feitas tendo em vista um contexto específico, para uma situação convencional oral e para uma audiência definida [...]". ${ }^{2}$ Isso vale para a mélica de Safo, ao contrário do que amiúde se imagina, por aproximação equívoca com a lírica moderna. Justamente a mélica, gênero que se define

\footnotetext{
1 "In light of Romanticism, Sappho's poetry has been read as an expression of the poet's inner feelings. According to this model, Sappho is a soloist, performing her songs and playing her lyre in a private space, a small-circle of same-sex companions" (LADIANOU. Female Choruses and Gardens of Nymphs, p. 343, tradução minha.) 2 " [...] there is no indication of the existence of poetic compositions from archaic or classical Greece, at least from Homer to Euripides, that were not composed with a view to a specific context, for a conventional oral situation and for a definite audience [...]" (FERRARI. Sappho's Gift, p. 12, tradução minha).
} 
pela performance - a canção para a lira, mais tarde nomeada lírica, quando na Biblioteca de Alexandria se tornou texto. Como ressalta Laura Swift, "Os gêneros gregos não são simplesmente artifícios literários, mas estão incrustrados num contexto ritual e performativo"; 3 na mélica, não raro as espécies se definem pela função de cada uma na vida prática da comunidade, externa à composição, mas a ela intrinsecamente vinculada. Os subgêneros mélicos estão, portanto, ligados à ocasião às quais destinam.

Vamos a Safo e à "Canção sobre a velhice":4

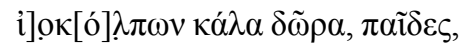

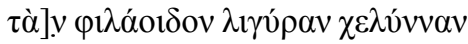

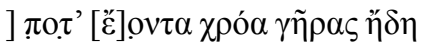

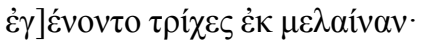

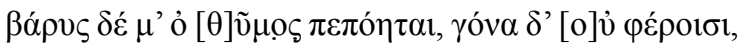

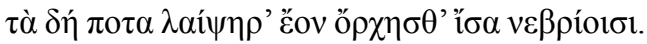

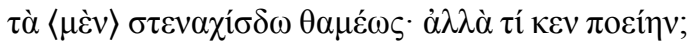

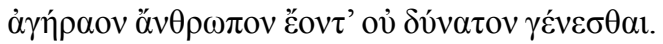

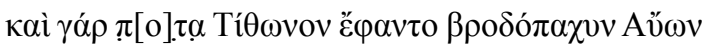

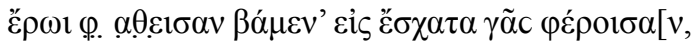

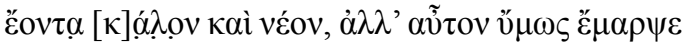

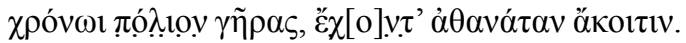

... (das Musas) de violáceo colo belos dons, ó meninas,

... a lira melodiosa, amante do canto;

outrora tenra (a pele), agora da velhice ...

... e (brancos) se tornaram os cabelos negros.

Pesado se me fez o peito, e os joelhos não me carregam os que um dia foram ágeis no dançar, como os da corça.

Isso lamento sem cansar. Mas que fazer?

\footnotetext{
3 "Greek genres are not simply literary devices, but are embedded in a ritual and performative context” (SWIFT. The Hidden Chorus, p. 14, tradução minha).

${ }^{4}$ Todos os fragmentos de Safo são citados na edição de VOIGT. Sappho et Alcaeus. A exceção fica por conta da "Canção sobre a velhice", citada na edição de OBBINK, no volume de GREENE e SKINNER. The New Sappho on Old Age, p. 7-16. A tradução, aqui com modificações, foi por mim antes publicada em Safo de Lesbos, p. 133-134; Lira grega, p. 130-132.
} 
Desprovido da velhice não se pode ser, sendo-se humano. 8

Pois, certa vez, dizem que Eos, róseos braços, com paixão ...(?) carregando Titono aos confins da terra, $\quad 10$ belo e jovem que era; mas similmente alcançou-o em tempo a grisalha velhice - ele que tinha imortal esposa. 12

O fragmento - lacunas e suplementos indicados por colchetes e reticências marcam tal condição - metapoético, preservado no Papiro de Colônia 21351 (século III a.C.), abre uma janela para a performance da canção. O termo paîdes (verso 1), que refere decerto as "meninas" prevalentes no universo sáfico, embora possa significar "crianças", instaura no início legível o "vós" a quem fala a voz da persona poética da canção associada à lira (verso 2) e aos "belos dons" (kála dôra, verso 1) das Musas [i]ok[ó]lpōn (verso 1) - de colos florais e festivos -, na dicção erotizante e marcadamente feminina dos qualificativos e das imagens.

O tema da velhice, com seus típicos traços físicos (versos 3-6), tormentos e preocupações (verso 5), sucede, ao que parece, o da própria canção, de modo articulado no âmbito da mélica ou canção coral, ${ }^{5}$ como indica a imagem pungente, nostálgica, dos “joelhos" (verso 5) que, rijos, já não suportam, não podem carregar (phéroisi, verso 5) os movimentos na dança (versos 5-6), contrastando com os leves, ágeis e jovens joelhos da corça que outrora - quando menina jovem, moça, como as coreutas a persona que lidera o coro exibiu. Claramente, é sua a voz nos versos, a cantar como se, sobrevindo-lhe a velhice, restasse-lhe dançar na canção que tematiza a atividade coral, a qual se faz fonte que viabiliza "a imortalidade poética e a juventude eterna". 6

Repare-se no modo como um dos efeitos mais reiterados da velhice na poesia grega antiga, o branquear dos cabelos e pelos, é atribuído como epíteto à própria velhice no final da canção (verso 12). E na dor resignada, advinda da constatação consolatória de que a velhice é inexorável e inelutável, porque é um dado da condição humana; daí o aspecto retórico da pergunta do verso 7. O exemplo mítico que sustenta

\footnotetext{
${ }^{5} \mathrm{O}$ gênero mais tarde será nomeado "lírica". Ver a respeito meus estudos prévios em RAGUSA. Lira, mito e erotismo, p. 24-42, e Lira grega, p. 11-19.

6 "[...] poetic immortality and eternal youth [...]". (LADIANOU. Female Choruses and Gardens of Nymphs, p. 366, tradução minha). Sobre a relação poesia-memóriaimortalidade, ver RAGUSA. Memória a terra prometida dos poetas, p. 143-152.
} 
a verdade sobre a velhice para os mortais é o da paixão de Eos, a deusa Aurora, pelo mortal Titono, belo jovem troiano, narrada sobretudo no Hino homérico V, a Afrodite (versos 218-238), datado do século VII a.C., e de autoria anônima. A deusa, tomada de paixão, pediu a Zeus que tornasse imortal seu amado, que era mortal, mas se esqueceu de pedir ao deus que o livrasse de outro grande mal próprio dos homens e estranho aos deuses (como lhes são estranhas a morte e a doença): a velhice, especialmente terrível no plano das relações eróticas, que são sempre físicas e, portanto, nutridas principalmente pela beleza do corpo. Assim, Titono tornou-se imortal, mas, envelhecendo eternamente, não mais atraiu a paixão de Eos que acabou por esquecê-lo trancado num quarto.

Concentremo-nos na coralidade entretecida ao novo fragmento de Safo, cujo termo chave é o verbo órkhēsthai (verso 6), que expressa a ação de dançar, na qual se conjugam a persona, como líder, e as "meninas" do verso 1, ao som da lira e com o favor das belas e femininas Musas (versos 1-2). A "Canção sobre a velhice" recorda, nessa imagem, o Fragmento 26, ${ }^{7}$ de Álcman, poeta de Esparta, ativo em fins de 620 a.C.. O breve texto é o que resta de um partênio, espécie mélica que consiste na canção para performance por coro de parthénoi, como são chamadas as moças ainda não casadas, as "virgens":

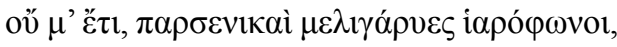

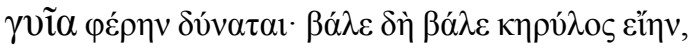

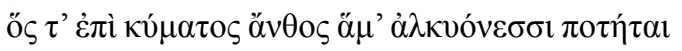

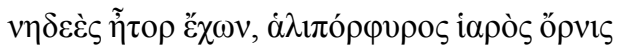

... a mim, não mais, ó virgens melicantantes, divas vozes, podem os membros carregar! Eia! Eia! - alcião eu fosse, que sobre a flor da onda com alcíones voa, coração intrépido, sacra ave maripurpúrea ... ${ }^{8}$

Nessas linhas, em dicção símil à do fragmento de Safo - com o uso de forma do verbo phérein ("carregar, portar, suportar"), e a referência aos membros ou joelhos -, o poeta dos partênios que tanto o afamaram

\footnotetext{
${ }^{7}$ Numeração e texto grego da edição de DAVIES. Poetarum melicorum Graecorum fragmenta, p. 76-78.

${ }^{8}$ Tradução minha, em RAGUSA. Lira grega, p. 58, citada com alterações.
} 
entre os antigos lamenta às "virgens" coreutas (parsenikai, 1), cujas vozes e cantar realça nos sucessivos epítetos do verso 1, a velhice que, fragilizando seus membros, faz-se impeditiva à sua atividade coral, na qual apenas pode prosseguir se oniricamente liberto, ou se conduzido pelas jovens que entoam suas canções, conforme a leitura mais condizente com a fonte dos versos, frisa o estudo de Gjert Vestrheim. ${ }^{9}$ Tal fonte é um tratado do escultor do século III a.C., Antígono de Caristo, que nas Maravilhas (23) oferece o trecho da canção de Álcman para ilustrar o relato segundo o qual, na espécie de ave que nomeia kērýlos, o macho, quando enfraquecido, é levado nas asas das fêmeas.

Para entendermos as imagens de Álcman e de Safo, que se rebatem, cabe recordar, junto a André Lardinois, ${ }^{10}$ que o poeta da mélica coral não apenas compunha as canções, mas preparava e acompanhava o khorós que a apresentava com dança coral - sentido básico do termo grego - e canto coral. Tal poeta, portanto, exercia o papel de khorodidáskalos ("mestre do coro") - no caso de Álcman, talvez com a intermediação de uma figura feminina entre ele e as virgens, como parece indicar seu famoso Fragmento 1, conhecido como "Partênio do Louvre". ${ }^{11}$ No trecho abaixo, o coro, em competição com outros no festival cívico-cultual em que se apresenta, enuncia um retórico catálogo de negativas, por meio do qual exibe as vestes e adereços de suas coreutas, estimula o olhar da audiência a contemplar sua beleza, e canta a relação estreita entre elas, de dimensão erótica:

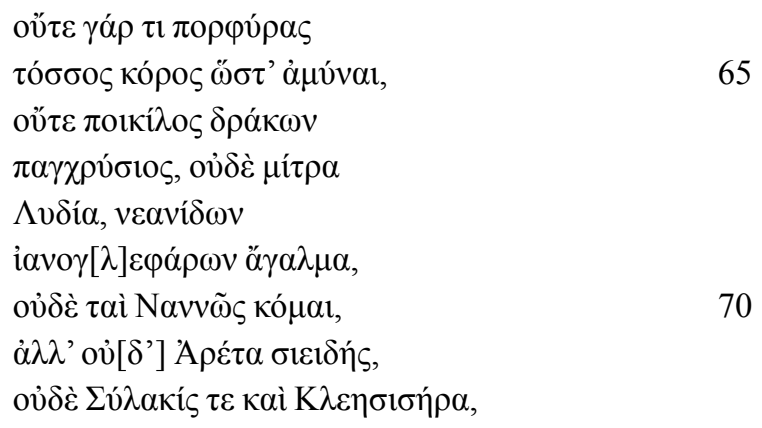

\footnotetext{
${ }^{9}$ VESTRHEIM. Alcman, fr. 26, p. 5-18.

${ }^{10}$ LARDINOIS. Subject and circumstance in Sappho's poetry, p. 79-80.

${ }^{11}$ Ver estudo detalhado prévio em RAGUSA. Lira, mito e erotismo, p. 101-208. Texto grego da edição de DAVIES. Poetarum melicorum Graecorum fragmenta, p. 24-35.
} 


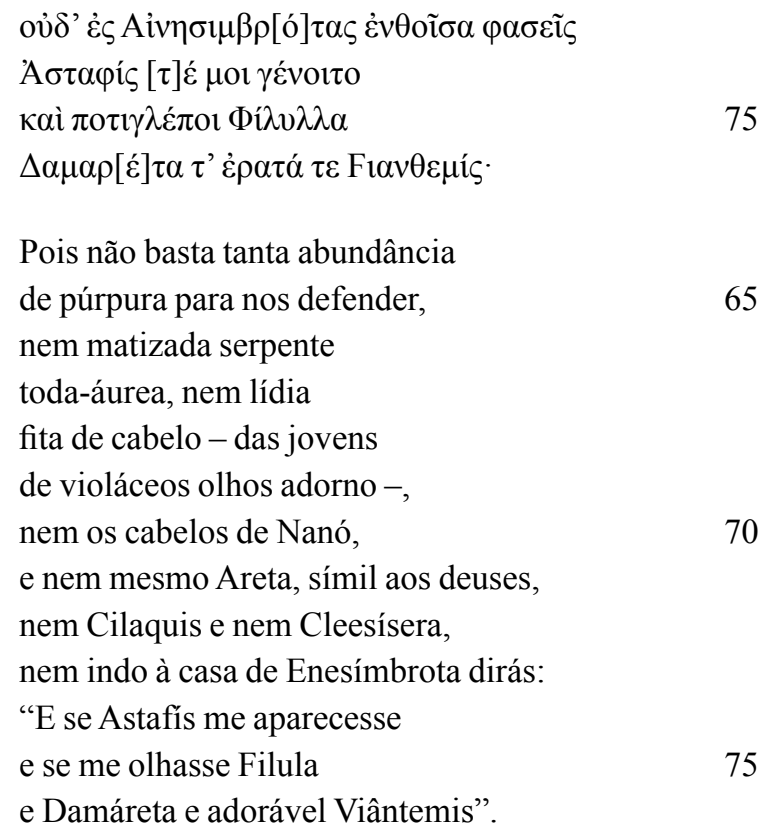

Como observa Laura Swift, "A desejabilidade das meninas é expressa pela beleza de seus corpos, em particular, de seus olhos e cabelos [...], e pelo esplendor luxuoso de seus acessórios". ${ }^{12}$ Destaco a mítra Lydía (versos 67-68), adereço aos cabelos sugestivo da "glória visual e do exotismo"13 que relaciona ao Oriente a ideia do luxo de que era fonte - a Lídia (Ásia Menor), à época orientalizante de Safo e Álcman, em especial. Em imagem de inegáveis contornos eróticos, a iluminarem a feminilidade das moças, são enunciados nove nomes: oito coreutas, das quais metade acha-se na performance, e metade, dela ausente. A nona figura, porém, Enesímbrota, não é uma coreuta, mas, sim, segundo um escólio à fonte do fragmento - o Papiro do Louvre (século I d.C.) - a didáskalos do coro, sua mestra, sua khorodidáskalos. Ela exerceria, junto às virgens, o papel de Álcman que, no mundo grego antigo, não atuaria

\footnotetext{
12 "The girls' desirability is expressed through the beauty of their bodies, in particular their eyes and hair [...], and through the luxurious splendor of their accessories" (SWIFT. Visual Imagery in Parthenaic Song, p. 259, tradução minha). 13 “[...] visual glory and exoticism [...]". (SWIFT. Visual Imagery in Parthenaic Song, p. 259, tradução minha).
} 
diretamente junto às parthénoi, dada a bem sabida separação que havia entre os universos masculino e feminino. ${ }^{14}$

Depreende-se da "Canção sobre a velhice" uma imagem que não apenas realça a dimensão coral de sua mélica, mas que indica que Safo teria desempenhado a função de khorodidáskalos junto às meninas a ela associadas, que abarcaria a orientação do desabrochar da feminilidade das parthénoi, futuras esposas a serem preparadas para tal condição, à semelhança do que se dá no caso bem documentado dos partênios de Álcman, por meio dos quais elas recebem uma formação e com os quais, na moldura institucional da performance na competição realizada no festival cívico-cultual em que se apresentam, são apresentadas à cidade, às famílias de seus futuros maridos, dos noivos em potencial. São atestados ${ }^{15}$ os grupos de meninas de origem aristocrática, nos quais elas recebiam a formação feminina específica, que incluía a atividade coral - canto, dança, música -, a reafirmação de valores ético-morais - sempre um elemento de força na mélica coral - e o conhecimento da tradição mítica, a preparação para o casamento designado gámos, termo cujo sentido básico é o "sexo" e, na medida em que este a consuma, a "boda". Tal preparação consiste no exercício da sensualidade, do erotismo, que, reitero, num cenário em que corriam paralelos os mundos feminino e masculino, dava-se internamente, no caso das parthénoi, ao universo feminino.

Observada a lógica da organização da vida de mulheres e de homens no mundo antigo, há que falar em homoerotismo, dimensão importante das formações corais femininas. Não há que falar, contudo, senão de modo anacrônico, modernizante, equívoco, em homossexualidade feminina ou lesbianismo. Ademais, como sublinha Maria Fernanda Brasete,

$\mathrm{Na}$ antiga cultura grega, efectivamente, o relacionamento erótico entre pessoas do mesmo sexo - que hoje apenas conhecemos de forma fragmentária e indirecta, através de escassos documentos literários e iconográficos - parecia integrar, naturalmente, a vida dos membros de uma sociedade, que, talvez por essa razão, nunca criou um léxico específico para o designar, nem nunca o entendeu de um modo discriminatório ou em termos psico-morais.

\footnotetext{
${ }^{14}$ Ver KATZ. The Divided World of Iliad VI, p. 19-44.

${ }^{15}$ Ver detalhado estudo de CALAME. Les choeurs de jeunes filles en Grèce archaïque.
} 
Mas falar de erotismo grego não é o mesmo que falar de sexualidade, porque, em primeiro lugar, não se trata de fenómenos atemporais e, por conseguinte, não podem ser descontextualizados das práticas sociais institucionalizadas numa determinada comunidade histórica. ${ }^{16}$

Considerando as ressonâncias entre Álcman e Safo, somente ouvidas após a publicação da "Canção sobre a velhice", e tendo ao fundo o quadro acerca dos grupos femininos de coros e da função de khorodidáskalos exercida pelos mélicos arcaicos na modalidade da canção coral, há que revisitar o corpus sáfico para repensar boa parte de seus elementos mais característicos: o predominante universo feminino; o apreço a vestes, adornos, e às ideias do luxo e da delicadeza; o marcante universo do gámos - apenas Safo nos legou epitalâmios, a espécie mélica da canção de casamento, nas eras arcaica e clássica; o erotismo e a prevalência de Afrodite nos fragmentos, em relação sempre muito estreita e cúmplice com a persona poética das canções $:{ }^{17} \mathrm{o}$ volumoso número de jovens personagens femininas identificadas individualmente ou referidas nos termos kórai, parthénoi, paîdes - que nomeiam necessariamente jovens moças não casadas, as quais, presentes com tanta força, levam André Lardinois a concluir que são elas "em toda probabilidade, o assunto da maior parte da poesia de Safo".$^{18}$ Há que revisar o corpus da poeta com atenção à coralidade, aspecto tão subestimado na leitura modernizante que insistiu em tomar por íntima, pessoal e privada a voz de seus versos, nos quais Safo manipula com perícia a linguagem de modo a criar a impressão de intimidade, afirma Ruth Scodel, ${ }^{19}$ os seus poemas dando-nos com frequência a ideia de canções para um grupo fechado feminino, privado. Há que percorrer esse corpus com a ideia mais sólida, consistente e embasada para compreendê-lo: de que "as composições de Safo tinham um propósito público, e se destinavam a

\footnotetext{
${ }^{16}$ BRASETE. Homoerotismo feminino na lírica grega arcaica, p. 292.

${ }^{17} \mathrm{Ver}$, sobre a representação de Afrodite em Safo, RAGUSA. Fragmentos de uma deusa. 18 "(...) young women are in all likelihood the subject of most of Sappho's poetry". (LARDINOIS. Subject and Circumstance in Sappho's Poetry, p. 70, tradução minha). ${ }^{19}$ SCODEL. Self-Correction, Spontaneity, and Orality in Archaic Poetry, p. 77.
} 
serem apresentadas pela própria Safo (ou por outro performer solo) ou por um coro diligentemente instruído". ${ }^{20}$

Revisito, pois, a mélica sáfica, tomando-a nos termos enunciados, e nos limites do que permite este estudo. Começo pelo grupo de canções menos enfocado, pois menos ajustável à leitura mais modernizante, os epitalâmios, mas não sem antes destacar a importância dessa espécie mélica no corpus da poeta, a despeito do fato de que são poucos e pequenos os fragmentos remanescentes. Isso porque o casamento (gámos) marca intensamente as canções sáficas que não estariam classificadas sob tal espécie, na edição da Biblioteca de Alexandria que primeiro organizou, em nove livros, todas as suas canções. Por exemplo, o Fragmento 44 ou "As bodas de Heitor e Andrômaca", ${ }^{21}$ de mélica narrativa em dicção epicizante. E ainda os Fragmentos 27 e $30:^{22}$

Fragmento 27:

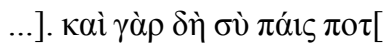

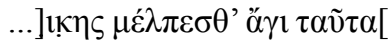

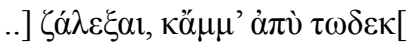

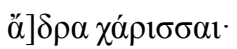

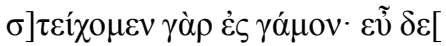

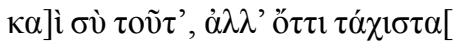

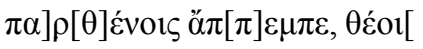

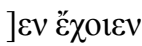

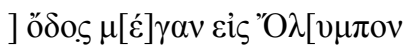

$\dot{\alpha}] v \theta \rho \omega[\pi \quad] \alpha i ́ \kappa .[$

... pois certa vez tu também, menina, ...

... cantar-dançar, vem!, essas coisas ...

... discutir ... e para nós ...

generosos deleites;

20 “(...) Sappho's compositions had a public, festive purpose, and were meant to be performed by Sappho herself (or by some other solo performer) or by a duly instructed chorus" (FERRARI. Sappho's Gift, p. 13, tradução minha).

${ }^{21}$ Ver meu estudo em RAGUSA. Heitor e Andrômaca, da festa de bodas à celebração fúnebre, p. 37-64.

${ }^{22}$ A tradução do Fragmento 27, aqui com modificações, acha-se em RAGUSA. Safo de Lesbos, p. 124. A do Fragmento 30 não foi antes publicada por mim. 


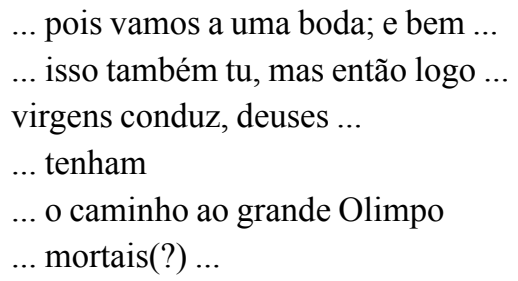

Fragmento 30:

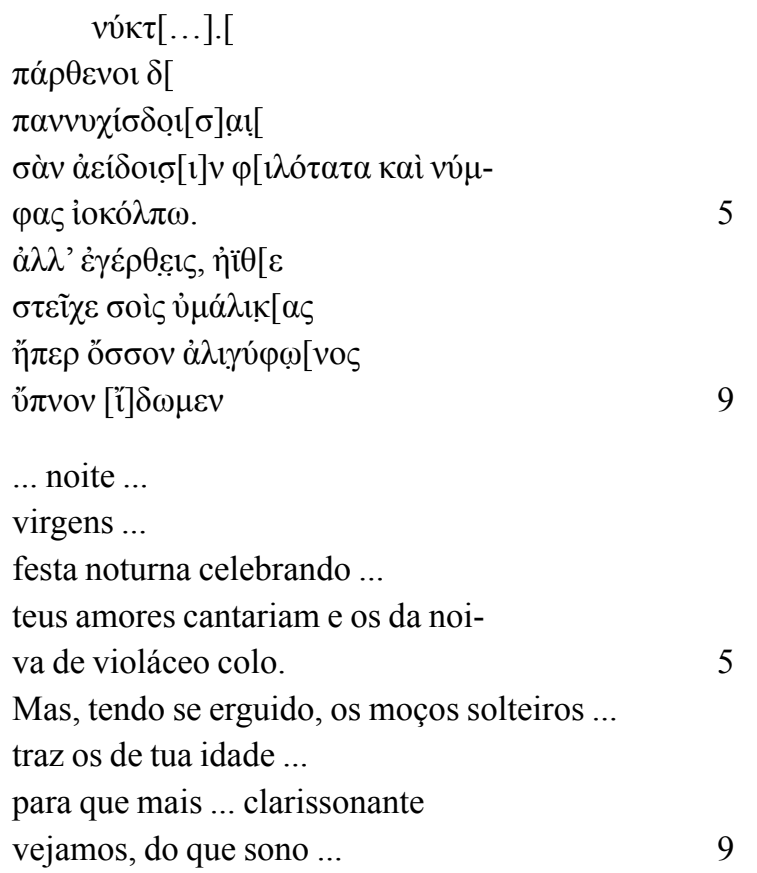

Notável em ambos a ideia da festa da boda, da qual participam com proeminência as parthénoi - por esse termo referidas - e a persona integrando o "nós" insistentemente desenhado, o grupo - de Safo, sem dúvida - ao qual é chamada a "menina" do verso 1 do Fragmento 27; o qual se encaminha à boda (es gámon, Fragmento 27, verso 8) ou nela já se acha (Fragmento 30), junto à bela e jovem noiva (versos 4-5) e aos demais convidados, inclusive os do noivo (verso 6). Notáveis o erotismo de que se revestem, porque próprio ao mundo do gámos, e realçado nas referências à beleza do corpo feminino, à kháris - o charme, a graça que 
suscita a reciprocidade, que ativa o prazer; e a ênfase na sonoridade das vozes, no cantar e no dançar, sobretudo no uso do verbo que nomeia com perfeição a mélica coral que é cantar e dançar sob música: mélpesth(ai), no Fragmento 27 (verso 5).

A voz coral se faz ouvir claramente em ambos os fragmentos que enfocam o casamento, o qual é, por sua vez, matéria dos epitalâmios em que a coralidade é patente. Cito um deles, o Fragmento 114, marcado pela jocosidade que é uma de suas constantes: ${ }^{23}$

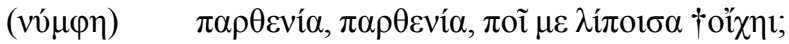

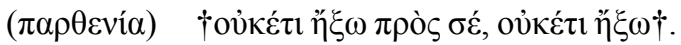

$$
\begin{aligned}
& \text { (noiva) Virgindade, virgindade, aonde vais, me abandonando? } \\
& \text { (virgindade) Nunca mais a ti voltarei, nunca mais voltarei }
\end{aligned}
$$

Entrelaçam-se no mundo do gámos, essencialmente feminino, a coralidade, o erotismo, a beleza. Entrelaça-se estreitamente à mélica sáfica essa trama que sustenta as relações e mesmo a função essencial do grupo de parthénoi, amiúde relacionado à persona de Safo nas composições, de modo coletivo ou individualizado. Grupo que parece não ter sido o único em Lesbos, e que tinha no gámos uma linha mestra. Recordo que, como disse logo no primeiro uso do termo parthénos, tratase de nomenclatura técnica para um status transicional na vida feminina, entre a tenra infância e a idade adulta, esta nomeada em gynée, termo que indica a participação no mundo do sexo a partir do casamento, numa trajetória sem desvios que podem conduzir às condições de hetera, espécie de cortesã, ou pórnē ("prostituta"), que implicam distintas condições sociais aqui não pertinentes. A moça virgem chegou ao amadurecimento sexual indicado na menarca; logo, o florescer de sua feminilidade e sensualidade se evidencia, tornando-a atraente e desejável. Como diz Mary Lefkowitz, ${ }^{24}$ os papéis sociais de esposa e mãe eram para os gregos os principais da gyné , da mulher; daí o interesse e a atratividade da parthénos, cuja energia vital deve convergir para o mundo do gámos que a institucionaliza e que lhe confere, feita a transição, um lugar social definido, frisa Giulia Sissa. ${ }^{25}$

\footnotetext{
${ }^{23}$ Tradução RAGUSA. Safo de Lesbos, p. 122; Lira grega, p. 127.

${ }^{24}$ LEFKOWITZ. The Last Hours of the Parthenos, p. 32.

${ }^{25}$ SISSA. Greek Virginity, p. 76.
} 
Como virgem prestes a adentrar o universo do sexo que deve consumar voluntariamente o casamento - assim ele se inicia sob bons augúrios -, a moça e o próprio gámos estão sob Afrodite; como mulher casada e responsável pela procriação e pela condução do oîkos (a "casa"), ela está sob Hera. Mas essa divisão não é rígida. Lembra Phoebe C. Segal que

O habilidoso emprego que faz Afrodite de sua beleza para seduzir seus amantes, seja marital ou extramaritalmente, provia um modelo para noivas e esposas. Afrodite estabelecia o exemplo de como incrementar a beleza com suntuosas vestes, joalheria, perfumes e cosméticos. [...] Como as evidências literária, visual e arqueológica demonstram, a influência de Afrodite na esfera da sexualidade era crucial à estabilidade de ambos o casamento individual e as comunidades gregas como um todo. ${ }^{26}$

E adiante, Segal acrescenta que

Era dever da esposa grega provocar seu marido à procriação, engajá-lo no ato sexual, e prover-lhe legítimos herdeiros. É, portanto, adequado que, na medida em que as meninas gregas, elas próprias, preparavam-se para se tornarem sedutoras, elas devessem invocar a orientação de, e buscar emular, Afrodite, a mais irresistível das deusas. ${ }^{27}$

26 “Aphrodite's skilled employment of her unparalleled beauty to seduce her lovers, whether martial or extramarital, provided a model for brides and wives. Aphrodite set the example for women of how to enhance their beauty with sumptuous clothing, jewelry, perfume, and cosmetics. (...) As the literary, visual, and archaeological sources demonstrate, Aphrodite's influence in the sphere of sexuality was crucial to the stability of both individual marriages and Greek communities as a whole" (SEGAL. The Paradox of Aphrodite, p. 63-64, tradução minha).

27 "It was the duty of the Greek wife to tease procreation of her husband, to engage him in the sexual act, and to provide him with legitimate heirs. It is only fitting that as Greek girls themselves prepared to become seductresses, they should have invoked the guidance of, and sought to emulate, Aphrodite, the most irresistible of all goddesses" (SEGAL. The Paradox of Aphrodite, p. 85, tradução minha). 
Afrodite que é, digo mais uma vez, a deusa mais presente em Safo, e a sua persona e a seu grupo estritamente ligada.

A formação do grupo de meninas de Safo, de Álcman e de outros mais de que temos evidências, tinha no gámos uma linha de força, mas abarcava mais do que isso, funcionando mesmo como instrumento de paideía, sublinha Christina Clark, porque era parte integral de um "processo que inculcava responsabilidade cívica, valores sociais e tradições [...] codificados na performance que servia para integrar o indivíduo do sexo feminino em seu contexto social". ${ }^{28}$ Nos grupos corais de meninas, ao exercício da feminilidade, do erotismo, da sensualidade, no vestir, no adornar e adornar-se, no cantar e dançar, articula-se a formação ético-moral pela reflexão sobre valores amiúde ativados pela tradição mítica que deve ser conhecida e que encerra, ainda, práticas relativas a etapas significativas da vida. Trata-se de um dado próprio de uma sociedade tradicional que, como bem lembra Anton Bierl, ${ }^{29}$ tinha no mito e no rito recursos de autodefinição e de identidade, razão pela qual esses dois elementos guardam lugar central na paideía da coralidade.

Nesse sentido, cito o Fragmento 140, possivelmente destinado à performance em festival das Adonias, que dramatiza o mito de tonalidade erótica-fúnebre da paixão de Afrodite pelo belíssimo Adônis, morto antes que realizasse suas potencialidades, no auge de sua virilidade, antes que com a deusa experimentasse a paixão:

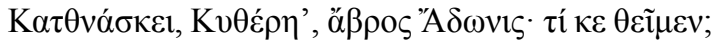

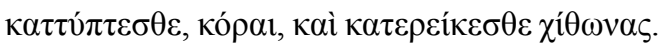

"Morre, Citereia, delicado Adônis. Que podemos fazer?"

"Golpeai, ó virgens, vossos seios, e lacerai vossas vestes ..."

28 " [...] a process that inculcated civic responsibility and social values and traditions [...] encoded in the performance, which served to integrate the individual female into her social context" (CLARK. The Gendering of the Body in Alcman's Partheneion 1, p. 144, tradução minha). Ver, sobre o tema da paideía na mélica, RAGUSA; BRUNHARA. Paideia na 'lírica' grega arcaica, p. 45-62.

${ }^{29}$ BIERL. Visualizing the Cologne Sappho, p. 311. 
Há aqui o mito, a deusa, a típica e ritualística gestualidade fúnebre, mas há algo de distinto que enfatizei outrora, ao estudá-lo e traduzi-lo, como acima: ${ }^{30}$ nas evidências sobre o festival das Adonias, do século $\mathrm{V}$ a.C. em diante, sobretudo, vemos que cabia exclusivamente às mulheres adultas (gýnai) - isto é, as casadas -, participarem das atividades rituais. Em Safo, porém, a quem devemos o mais antigo testemunho desse festival, em conformidade com a lógica paidêutica da formação coral de que estava encarregada, a dramatização da dor do luto é protagonizada por kórai, as meninas virgens orientadas por Afrodite, que lhes ensina como prantear a morte de Adônis - ou, por outra, permitindo que vivenciem a experiência fúnebre na encenação dramática da canção.

A força da coralidade na mélica sáfica também se revela nas reiteradas práticas de atividades próprias das de um coro, como observa Lardinois, ${ }^{31}$ com destaque para o trançar de guirlandas floridas, o adornarse, o perfumar-se, e o participar de ritos. Eis alguns, vários, fragmentos pertinentes:

\section{Fragmento $81:^{32}$}

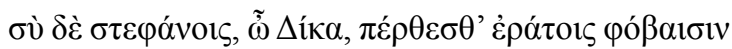

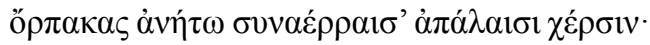

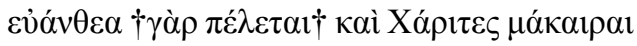

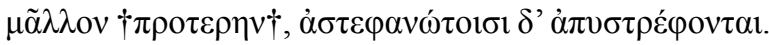

... e tu, ó Dica, cinge teus cachos com amáveis guirlandas, tramando raminhos de aneto com tuas mãos macias;

pois mesmo as Cárites venturosas voltam-se às coisas floridas, sobretudo, mas ao não-coroado dão as costas ...

É possível que a canção se destine a uma festividade nupcial, o que explicaria a imagem de Dica em evidência: bela, jovem, erotizada - ela poderia ser a noiva. Para tal festa, como para qualquer outra, a guirlanda é elemento essencial, e há que saber trançá-las. E o prazer, o charme, o regozijo são realçados pela mais do que adequada presença

\footnotetext{
${ }^{30}$ Ver RAGUSA. Fragmentos de uma deusa, p. 356-361; Safo de Lesbos, p. 84; Lira grega, p. 130.

${ }^{31}$ LARDINOIS. Subject and Circumstance in Sappho's poetry, p. 70.

${ }^{32}$ Tradução, aqui com modificações, em RAGUSA, Safo de Lesbos, p. 124.
} 
das próprias Cárites, as deusas Graças, que com frequência integram o cortejo de Afrodite na tradição mítico-poética e iconográfica, protetoras da juventude vegetal e humana.

Agora, o Fragmento 94: ${ }^{33}$

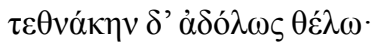

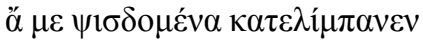

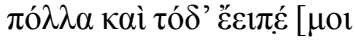

$\ddot{\omega} \mu \mu^{\prime} \dot{\omega} \varsigma \delta \varepsilon \tilde{\varepsilon} v \alpha \pi \varepsilon \pi[o ́ v \theta] \alpha \mu \varepsilon v$,

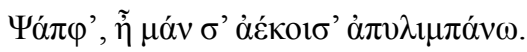

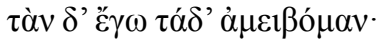

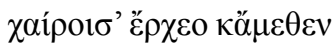

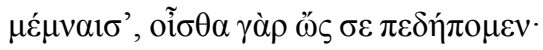

$\alpha \grave{i} \delta \grave{\varepsilon} \mu \eta \dot{\eta}, \dot{\alpha} \lambda \lambda \alpha \dot{\alpha} \sigma^{\prime} \varepsilon^{\prime} \gamma \omega \theta \dot{\varepsilon} \lambda \omega$

ö $\mu v \alpha 1 \sigma \alpha 1[\ldots .()] ..[. .().] . \varepsilon \alpha 1$

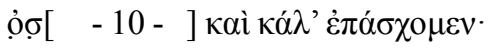

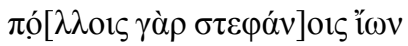

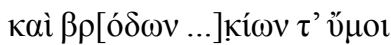

$\kappa \alpha . .[-7$ - ] $\pi \grave{\alpha} \rho \check{\varepsilon} \mu \mathrm{o} \pi<\varepsilon>\rho \varepsilon \theta \dot{\eta} \kappa \alpha<0>$

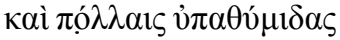

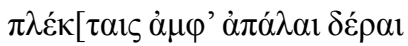

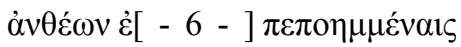

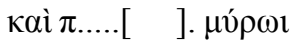

$\beta \rho \varepsilon v \theta \varepsilon i ́ \omega !$ [ ] ]

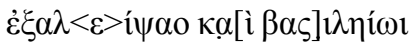

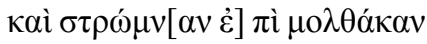

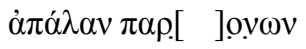

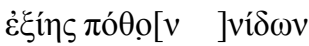

$\kappa \omega \vartheta ̋ \tau \varepsilon \tau 1 \sigma[\quad$ ơ̋ $] \tau \varepsilon \tau \imath$

ĩoov oủ $\delta$ 'े [ ]

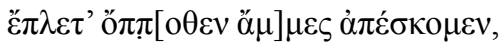

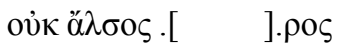

${ }_{33}$ Tradução, aqui com modificações, em RAGUSA, Safo de Lesbos, p. 99-100; Lira grega, p. 119-121. 
... morta, honestamente, quero estar";

ela me deixava chorando

muito, e isto me disse:

"Ah!, coisas terríveis sofremos,

"Ó Safo, e, em verdade, contrariada te deixo". 5

E a ela isto respondi:

"Alegra-te, vai, e de mim

te recorda, pois sabes quanto cuidamos de ti;

mas, se não, quero eu te

lembrar ...

... e coisas belas experimentamos;

pois com muitas guirlandas de violetas

e de rosas ... juntas

... ao meu lado pusestes,

e muitas olentes grinaldas

trançadas em volta do tenro colo,

de flores ... feitas;

e ... com perfume

de flores ...

digno de rainha, te ungiste,

e sobre o leito macio

tenra ...

saciavas (teu) desejo ...

não havia ... nem algum

santuário, nem ...

de que estivéssemos ausentes,

nem bosque ...

Nessa canção de caráter fortemente dramático, a persona se autonomeia "Safo". É esta a identidade da voz poética de boa parte das composições do corpus preservado de sua mélica, amiúde articulada ao "nós" - o grupo de parthénoi - e engajada em atividades corais, festivas, de tonalidades cultuais. A autonomeação ocorre em outras canções (Fragmentos 1 e 133) e, em verdade, em diversos poetas de outros gêneros, desde Hesíodo (ativo em c. 700 a.C.), no poema didático-cosmogônico Teogonia (versos 22-35). Logo, na perspectiva da poesia de tradição, na Grécia eminentemente oral que se configura 
como song-culture até meados do século $\mathrm{V}$ a.C.,${ }^{34}$ não deve ser observada em chave biografizante, como quiseram antigos e modernos, mas de autodramatização relativa à performance e associada ao motivo da imortalização pela memória na canção. ${ }^{35}$ Recorro a Marilyn B. Skinner, segundo quem

[...] dada a função normal do poeta grego arcaico como falante-representante indicado por sua - dele(a) comunidade, é bem mais provável que a autoestilização de Safo enquanto o sujeito (ego) que deseja, junto com seu extenso estoque de temas, formas de versos e melodias, tropos e imagens, fosse largamente tradicional, um produto de muitas gerações de um esforço criativo local. [...] Abordando as canções de Safo como discursos sociais, evitamos os difíceis problemas de representação envolvidos no tratamento do texto como um espelho fiel da subjetividade única de um autor. ${ }^{36}$

$\mathrm{Na}$ recordação de quem fica, a cena de despedida vem à tona marcada pela tristeza de quem parte - "ela" -, e pela fala consolatória de quem busca, depois de superar a própria tristeza (verso 1), alegrar - levar kháris (verso 7) a quem se vai a contragosto, por necessidade (verso 5) - pela memória das experiências e atividades festivas, rituais, eróticas, corais, enfim, compartilhadas no âmbito do grupo conduzido por Safo, e integrado de forma transitória pelas parthénoi que vêm e vão, e que ali são cuidadas, como ressalta a persona nos versos 7-8, de

\footnotetext{
${ }^{34}$ Ver, para estudo da poesia como performance na Grécia antiga, HERINGTON. Poetry into Drama, p. 3-40.

${ }^{35}$ Ver estudo em RAGUSA. Memória a terra prometida dos poetas, p. 143-152.

36 " [...] given the normal function of the archaic Greek poet as appointed spokesperson for his or her community, it is far more likely that Sappho's self-stylization as desiring ego, along with her extensive stock of themes, verse forms and melodies, tropes and imagery, was largely traditional, a product of many generations of local creative endeavor. [...] By approaching these songs as social discourses, we avoid the sticky problems of representation involved in treating a text as the faithful mirror of an author's unique subjectivity" (SKINNER. Woman and Language in Archaic Greece, p. 183, tradução minha).
} 
maneira solidária e cúmplice. Veja-se a imagem do "prazer sensual do dormir junto entre coevos e os laços afetivos que lhe seguem". ${ }^{37}$

O movimento transicional é também nítido nos grupos femininos dos partênios de Álcman, como mostra o Fragmento 3 (Davies), canção em que "as disciplinas musical e emocional são inseparavelmente emparelhadas em ambas a performance e a linguagem do poema", ${ }^{38}$ afirma Anastasia Peponi. Na sequência mais legível (versos 61-85), em dicção erotizada, e no jogo típico da $1^{a}$ pessoa do plural pela $1^{\mathrm{a}}$ do singular, o coro canta o afastamento que de si vai tomando Astimelusa o "mimo da cidadela", diz seu nome, explicado no verso 74 -, à medida em que adentra o mundo da cidade, entenda-se, o gámos, o casamento pelo qual deixa para trás a condição de parthénos e o convívio entre as coreutas que não mais a alcançam (versos 64-8). Trata-se de experiência que ouvimos na mélica sáfica, representada com frequência no contexto da coralidade, ressalta Peponi. ${ }^{39}$ Cito a canção de Álcman: ${ }^{40}$

\begin{tabular}{|c|}
\hline 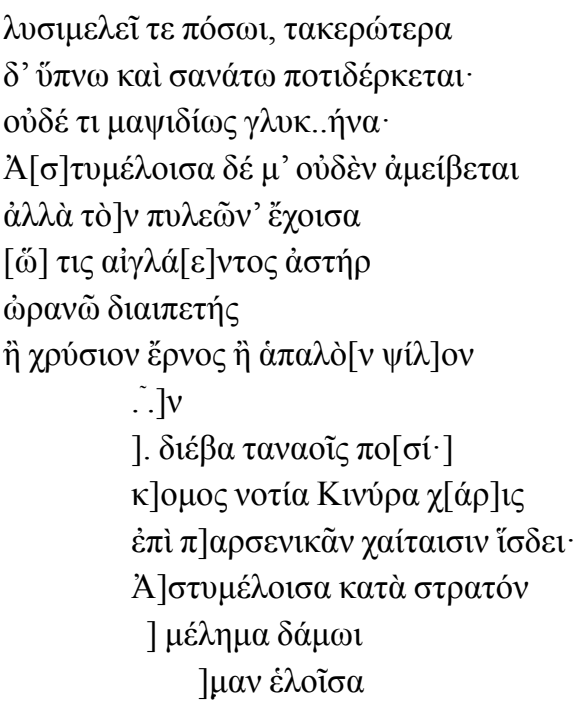 \\
\hline
\end{tabular}

37 “[...] sensual pleasure of sleeping together among age-mates and the affectionate ties that follow" (FERRARI. Sappho's Gift, p. 141, tradução minha).

38 " [...] musical and emotional disciplines are inseparably paired in both the poem's enactment and language" (PEPONI. Sparta's prima ballerina, p. 351, tradução minha). ${ }^{39}$ PEPONI. Sparta's prima ballerina, p. 353.

${ }^{40}$ Tradução, com alterações, de RAGUSA, Lira grega, p. 53-54. 
]$\lambda \varepsilon ́ \gamma \omega \cdot$

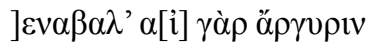

].[.]ía

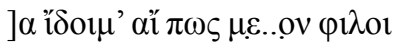

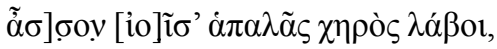

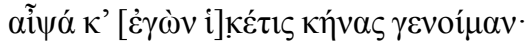

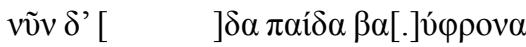

$\pi \alpha 1 \delta 1 .[\quad] \mu^{\prime}$ '

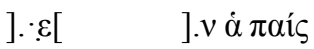

] xápıv.

... e com desejo deslassa-membros, e mais derretidamente do que o sonho ou a morte me fita;

e não em vão doce(?)...;

Astimelusa nada me responde,

mas segurando a guirlanda,

como esplêndida estrela

do céu radiante,

ou áureo broto ou tenra pluma

... atravessou com finos pés

... a graça úmida de Ciniras

assenta-se sobre as melenas das virgens;

Astimelusa pela multidão

... mimo do povo

... ela pegando ...

... eu digo;

... pois se argêntea

... eu veria, se acaso ... (amasse?)

perto (me) vendo, tomasse a tenra mão

de pronto dela eu me tornaria suplicante;

e agora ... menina de fundo juízo

meninas(?) ... a mim ela tendo

... a menina 
Ressalta Laura Swift ${ }^{41}$ que o poder que emana de Astimelusa projeta-se na canção, como é típico do contexto erótico, pelo olhar; e sua imagem se nutre dos também típicos elementos de luz e juventude, com referências aos cabelos, aos pés, à pele das mãos, aos perfumes - Ciniras é rei mítico e sacerdote de Afrodite em Chipre, ilha dileta da deusa e conhecida pela fabricação e exportação de fragrâncias na Antiguidade. Note-se ainda a intensidade cinética da coralidade, realçada na análise de Anastasia-Erasmia Peponi. ${ }^{42}$ Ela afirma que, séculos antes da discussão que fará Platão (c. 429-348 a.C.) nas Leis (653e-654e) sobre as relações entre khoreía e paideía, Álcman

estava muito provavelmente praticando um modelo coral que, pelo entretecer da mousikê com a emoção, tinha o poder de verbalizar, destilar e transformar prazer (hedonê) e dor (lupê). Não espanta, então, que a distância física e a falta do toque sejam transmutados pelo coro naquela necessária distância estética, a partir da qual uma Astimelusa em levitação pode ser imaginada e apreciada de três modos alternativos (66-8): como uma estrela voando pelos céus brilhantes, como um ramo de ouro, ou como uma pluma macia. Nessa total transformação da dor do desejo em prazer estético, o coro feminino, a audiência interna [da performance da canção], parece estar sugerindo um modelo de contemplação benéfico à [audiência] externa, masculina [que vê a performance no festival cívico-cultual em que é apresentada em competição]. Ou seja, antes de seu compromisso nupcial, Astimelusa, melêma ['mimo'] do dêmos [da 'comunidade'] de Esparta, figura meio real, meio imaginária, pode corporificar, por algum tempo, o engajamento estético da cidade. ${ }^{43}$

\footnotetext{
${ }^{41}$ SWIFT. Visual Imagery in Parthenaic Song, p. 262.

${ }^{42}$ PEPONI. Sparta's prima ballerina, p. 354-357.

43 " [...] was most likely practising a choral model that by its interweaving of mousikê with emotion had that power to address, distil, and transform pleasure (hedonê) and pain (lupê). No wonder, then, that physical distance and lack of touch are transmuted by the chorus into that necessary aesthetic distance, from which a levitated Astymelousa can be imagined and enjoyed in three alternative ways (66-8): as a star flying through the shiny heavens, as a golden branch, or a soft down. In this total transformation of desire's pain into aesthetic pleasure, the female chorus, the internal audience, seems to
} 
Outras canções de recordação de quem partiu do grupo de que foi parte se disseminam no corpus de Safo, como a bem conhecida "Ode a Anactória" (Fragmento 16). Lembro outra, menos enfocada, no Fragmento $96 ;{ }^{44}$ cito os versos mais legíveis:$$
] \sigma \alpha \rho \delta .[. .]
$$

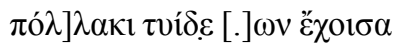$$
\dot{\omega} \sigma \pi .[\ldots] . \omega \dot{0} \mu \varepsilon v, .[\ldots] . . \chi[. .]
$$$$
\sigma \varepsilon \dagger \theta \varepsilon \alpha \sigma i \kappa \varepsilon \lambda \alpha v \dot{\alpha} \rho \mathrm{l}-
$$

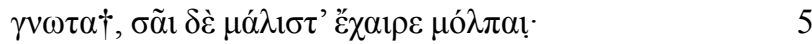

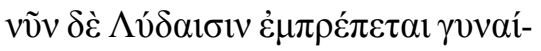

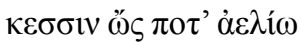

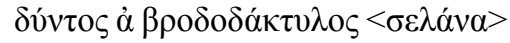

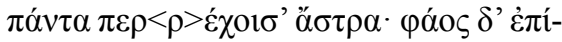$$
\sigma \chi \varepsilon 1 \theta \alpha \dot{\lambda} \alpha \sigma \sigma \alpha v \dot{\varepsilon} \pi \text { ' } \dot{\lambda} \lambda \mu v_{\rho} \alpha \nu
$$

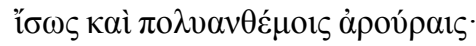

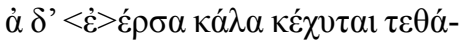

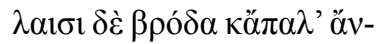

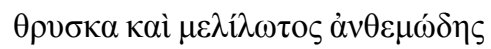

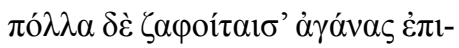

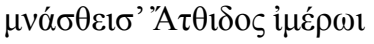

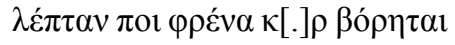$$
\text { ... Sárdis(?) ... }
$$$$
\text { amiúde para cá ... ela tendo }
$$ \\ ... qual deusa manifes- \\ ta, e (ela) sobretudo se deleitava com teu canto-dança. 5 \\ Mas agora ela se sobressai entre lídias mu- \\ lheres como, depois do sol \\ posto, a dedirrósea lua \\ supera todas as estrelas; e sua luz se es- \\ parge por sobre o salso mar \\ e igualmente sobre multiflóreos campos.

be suggesting a model of contemplation for the benefit of the external, the male one. That is, before her bridal engagement, Astymelousa may embody for a while the city's aesthetic engagement" (PEPONI. Sparta's prima ballerina, p. 362, tradução minha). ${ }^{44}$ Para estudo detido, ver RAGUSA, Fragmentos de uma deusa, p. 235-247. 
E o orvalho é vertido em beleza, e vice-

jam as rosas e o macio ce-

refólio e o trevo-mel em flor.

E (ela) muito agitada de lá para cá, a re-

cordar a gentil Átis com desejo;

decerto frágil senso ... se consome.

No convívio do passado, canto e dança, expressos em mólpai (verso 5); prazer, expresso na forma do verbo khaírein (verso 5); erotismo e universo feminino de beleza só descritível na imagética dos elementos naturais, o principal, a "lua". No presente, não mais em Lesbos, mas no reino da Lídia (Ảsia Menor) está "ela" que deixou para trás, a sofrer, Átis, figura feminina outras vezes nomeada em Safo, pelo elo rompido, a amizade intensificada pela dimensão erotizada da formação para o mundo do sexo. Note-se que "ela" que, no passado, estava no meio do "nós" integrado por Átis e outras parthénoi, e liderado pela persona poética de Safo, mudou de status no presente, pois sua beleza não mais é comparável à de moças, e, sim, à de gynaíkessin - as "mulheres" lídias (versos 6-7). E "ela" - eis o consolo para Átis -, embora tenha partido para sempre, jamais olvidará "as nostálgicas memórias" ${ }^{45}$ da amizade, dos laços intensos com ela forjados no contexto da coralidade paidêutica do grupo que, como se vê, experimenta a experiência da perda, a qual sem dúvida encarece a importância das relações interpessoais. Pela linguagem da coralidade e da poética sáfica se neutraliza o trauma da separação, como observa Ferrari ${ }^{46}$ - uma vivência que toda parthénos terá na transição para a condição de gynế, de mulher, futura esposa e mãe. Afirma Ellen D. Reeder, a propósito:

O dia do casamento é o dia do evento mais relevante que ocorreria na vida de uma mulher, e suas ramificações são enormes. O casamento é um momento de severa crise na vida de uma menina, na medida em que ela abandonava sua infância e os cuidados de sua mãe, para fisicamente adentrar um mundo carregado da ansiedade da sexualidade, da apreensão quanto à coexistência com a sogra, e do terror da maternidade - um risco potencialmente fatal à vida. ${ }^{47}$

\footnotetext{
45 “[...] nostalgic memories [...]" (FERRARI. Sappho's Gift, p. 51, tradução minha). ${ }^{46}$ FERRARI. Sappho's Gift, p. 52.

47 "Her wedding was the single most important event that would ever occur in a woman's life, and its ramifications were enormous. The young bride left her home
} 
Para a parthénos, o casamento é uma espécie de morte, e são muitos os paralelos entre as cerimônias que, cada uma a seu tempo, celebram ambas as transições.

Voltando a Safo e ao Fragmento 96, nele percebemos que o grupo da poeta não agregava somente moças de Lesbos, mas de outras partes do mundo próximo à ilha, mesmo na Ásia Menor, prova de seu prestígio. E ainda, nos Fragmentos 94 e 96, como no partênio de Álcman, o movimento transicional no grupo, característico do próprio status igualmente transicional das parthénoi que recebiam essa paideía coral, em que, diz Bierl, "Música, ritmo, e o movimento coletivo da canção e da melodia levam a um entendimento aprofundado da beleza", ${ }^{48}$ o qual é, por sua vez, intensificado pela dimensão homoerótica das meninas que adquirem

uma intensificada sensibilidade e maior insight com relação à natureza, ao ambiente, ao cosmos e aos valores aristocráticos. Esse treinamento comum também provê uma familiaridade estética com os meios que fortalecem esses sentimentos - palavras, música, e dança -, os quais, juntos, fazem a mediação da poesia visual. [...] As nobres meninas são assim preparadas para seus casamentos, para os quais precisam de ambas as belezas física e interna, e na recordação de suas experiências compartilhadas a beleza é mantida viva, mesmo após terem deixado a comunidade de Safo. ${ }^{49}$

and the supervision of her mother to enter the house of her mother-in-law who would now be the most central female figure in her life. Marriage was a moment of severe crisis in a girl's life, as she abandoned childhood and her mother's care a physically new world fraught with the anxiety of sexuality, the apprehension of coexistence with a mother-in-law, and the terror of the life-threatening peril of childbirth" (REEDER. Women and Men in Classical Greece, p. 22, tradução minha).

48 "Music, rhythm, and collective movement to song and melody lead to a deeper understanding of beauty" (BIERL. Visualizing the Cologne Sappho, p. 311, tradução minha).

49 " [...] an increased sensitivity and greater insight into nature, the environment, the cosmos, and aristocratic values. This common training also provides an aesthetic acquaintance with the media that strengthen these feelings - words, music, and dance - which together mediate visual poetry. [...] The noble girls are thus prepared for their marriage, for which they need both physical and inner beauty, and in the recollection 
Este é o esforço de ambos os Fragmentos 94 e 96, do discurso que revive no presente a coralidade feminina em essência, compartilhada no passado - no caso daquele fragmento, de modo acentuadamente visual e sinestésico, observa Ladianou, ${ }^{50}$ que estende à audiência essa experiência na concretude do hic et nunc, do aqui e agora em que se enlaçam a líder do coro, as coreutas e quem as ouve e contempla.

\section{Referências}

BIERL, Anton. Visualizing the Cologne Sappho. In: CAZZATO, Vanessa; LARDINOIS, André (ed.). The Look of Lyric: Greek Song and the Visual. Leiden: Brill, 2016. p. 307-342.

BRASETE, Maria Fernanda. Homoerotismo feminino na lírica grega arcaica. In: FIALHO, Maria do Céu et alii (org.). A sexualidade no mundo antigo. Coimbra: Centro de Estudos Clássicos e Humanísticos U. Coimbra, 2009. p. 289-303.

CALAME, Claude. Les choeurs de jeunes filles en Grèce archaïque. Rome: Ateneo \& Bizarri, 1977. 2 v.

CLARK, Christina A. The Gendering of the Body in Alcman's Partheneion 1. Helios, Lubbock, v. 23, n. 2, p. 143-172, 1996.

DAVIES, Malcom. (ed.). Poetarum melicorum Graecorum fragmenta. Oxford: Clarendon, 1991. v. 1.

FERRARI, Franco. Sappho's Gift: The Poet and Her Community. Tradução de Benjamin Acosta-Hughes e Laura Prauscello. Ann Arbor: Michigan Classical Press, 2010.

GREENE, Ellen; SKINNER, Marilyn B. (ed.). The New Sappho on Old Age. Washington D.C.: Center for Hellenic Studies, 2009.

HERINGTON, John. Poetry into Drama: Early Tragedy and the Greek Poetic Tradition. Berkeley: University of California Press, 1985.

of their shared experiences beauty is kept alive even after they have left the Sapphic community" (BIERL. Visualizing the Cologne Sappho, p. 311, tradução minha).

${ }^{50}$ LADIANOU. Female Choruses and Gardens of Nymphs, p. 346. 
KATZ, Marylin A. The Divided World of Iliad VI. In: FOLEY, Helen P. (ed.). Reflections of Women in Antiquity. Philadelphia: Gordon and Breach, 1992. p. 19-44.

LADIANOU, Katerina. Female Choruses and Gardens of Nymphs: Visualizing Chorality in Sappho. In: CAZZATO, Vanessa; LARDINOIS, André (ed.). The Look of Lyric: Greek Song and the Visual. Leiden: Brill, 2016. p. 343-369. DOI: https://doi.org/10.1163/9789004314849_015.

LARDINOIS, André. Subject and Circumstance in Sappho's Poetry. Transactions of the American Philological Association, Baltimore, v. 124, p. 57-84, 1994. DOI: https://doi.org/10.2307/284286.

LEFKOWITZ, Mary. The Last Hours of the Parthenos. In: REEDER, Ellen D. (ed.). Pandora's Box: Women in Classical Greece. Princeton: University Press, 1995. p. 32-39.

PEPONI, A. Sparta's Prima Ballerina: Choreia in Alcman's Second Partheneion (3 PMGF). Classical Quarterly, Cambridge (Inglaterra), v. 57, n. 2, p. 351-362, dez. 2007.

RAGUSA, Giuliana (org. e trad.). Lira grega: antologia de poesia arcaica. São Paulo: Hedra, 2013. DOI: https://doi.org/10.1017/ S0009838807000444.

RAGUSA, Giuliana. (org. e trad.). Safo de Lesbos: hino a Afrodite e outros poemas. São Paulo: Hedra, 2011.

RAGUSA, Giuliana. Fragmentos de uma deusa: a representação de Afrodite na lírica de Safo. Campinas: Editora da Unicamp, 2005. [Apoio: Fapesp].

RAGUSA, Giuliana. Heitor e Andrômaca, da festa de bodas à celebração fúnebre: imagens épicas e líricas do casal na Ilíada e em Safo (Fr. 44 Voigt). Caliope, Rio de Janeiro, n. 15, p. 37-64, 2006.

RAGUSA, Giuliana. Lira, mito e erotismo: Afrodite na poesia mélica grega arcaica. Campinas: Editora da Unicamp, 2010. [Apoio: Fapesp].

RAGUSA, Giuliana. Memória, a terra prometida dos poetas: o tema na mélica grega arcaica. Forma Breve, Aveiro, n. 15, p. 143-152, 2018.

RAGUSA, Giuliana; BRUNHARA, Rafael. Paideia na 'lírica' grega arcaica: a poesia elegíaca e mélica. Revista Filosofia e Educação, Campinas, n. 9, p. 45-62, 2017. DOI: https://doi.org/10.20396/rfe. v9i1.8648422. 
REEDER, Ellen D. Women and Men in Classical Greece. In:

(org.). Pandora's Box: Women in Classical Greece. Princeton: University Press, 1995. p. 20-31.

SCODEL, Ruth. Self-Correction, Spontaneity, and Orality in Archaic Poetry. In: WORTHINGTON, Ian (org.). Voice into Text: Orality and Literacy in Ancient Greece. Leiden: Brill, 1996. p. 59-79. DOI: https:// doi.org/10.1163/9789004329836_005.

SEGAL, Phoebe C. The Paradox of Aphrodite. In: KONDOLEON, Christine; SEGAL, Phoebe C. (org.). Aphrodite and the Gods of Love. Boston: MFA Publications, 2011. p. 63-105.

SISSA, Giulia. Greek Virginity. Tradução de Arthur Goldhammer. Cambridge: Harvard University Press, 1990.

SKINNER, Marilyn B. Woman and Language in Archaic Greece, or, Why is Sappho a Woman? In: GREENE, Ellen (ed.). Reading Sappho: Contemporary Approaches. Berkeley: University of California Press, 1996. p. 175-192.

SWIFT, Laura. A. The Hidden Chorus: Echoes of Genre in Tragic Lyric. Oxford: University Press, 2010. DOI: https://doi.org/10.1093/acprof:o so/9780199577842.001.0001.

SWIFT, Laura. Visual Imagery in Parthenaic Song. In: CAZZATO, Vanessa; LARDINOIS, André (ed.). The Look of Lyric: Greek Song and the Visual. Leiden: Brill, 2016. p. 255-287. DOI: https://doi. org/10.1163/9789004314849_012.

VESTRHEIM, Gjert. Alcman fr. 26: A Wish for Fame. Greek, Roman, and Bizantine Studies, Durham, v. 44, p. 5-18, 2004.

VOIGT, Eva-Maria (ed.). Sappho et Alcaeus: Fragmenta. Amsterdam: Athenaeum, Polak \& Van Gennep, 1971.

Recebido em: $1^{\circ}$ de setembro de 2019. Aprovado em: 2 de dezembro de 2019. 